the original octants, since any octahedron can, by adding small tetrahedrons to alternate faces, be extended to positive and negative large tetrahedrons. By means of this fortunate geometrical fact the orthodromic service of this double set of tangent planes exceeds by far the service of any single plane possible.

Supplementing this variant are simple graphic diagrams for $(a)$ continuing any line from chart to chart around the world, (b) joining any two points anywhere in one great circle, (c) measuring with precision all distances whether across any one, four or six charts, $(d)$ converting all forward and retro-azimuths to true compass directions or vice versa to or from any point on the entire globe.

The 'Butterfly Map' is deliberately designed and mathematically detailed to meet the needs of ever growing world-wide problems and to help mankind above all things "to learn to think planetarily".

\section{Atmospheric Tides}

$\mathrm{I}^{\mathrm{N}}$ a paper entitled "Tides in the Atmosphere", in Scientific Monthly for August, J. Bartels gives a simple summary of our present knowledge concerning phenomena that would interest many people but for the intricate mathematics involved. $\mathrm{He}$ states that these tides have been studied lately by magneticians rather than by meteorologists because they assist the interpretation of terrestrial magnetic data. The main facts deserve, however, to be noted by meteorologists and others for whom this summary should, therefore, be of value.

It appears that our understanding of atmospheric tides still rests mainly on the resonance theory of Kelvin, developed later by Rayleigh and Margules. Analysis of long series of barograms has brought to light several small periodic variations of atmospheric pressure due to the tidal action, either thermal or gravitational, of the sun and the moon, and tidal theory is largely successful in accounting for them. The relative simplicity of atmospheric as opposed to oceanic tides, it may be noted, is due to the fact that the resonance properties of the atmosphere as a whole enhance the world-wide oscillations and repress local irregularities. Of the solar tides there are the travelling 12 hour wave with maxima at 10 a.m. and 10 p.m. local mean time, the 12 hour wave between polar and equatorial regions, with fixed nodes in about latitudes $35^{\circ} \mathrm{N}$. and $\mathrm{S}$., the 8 hour travelling wave, which shows a reversal of phase between summer and winter, and the 24 hour travelling wave. The two 12 hour waves and the 8 hour wave are appreciable mainly because the resonance factor for them is large. In the case of the $\mathbf{2 4}$ hour wave on the other hand, because of the very small resonance factor, the amplitude is very small in spite of the magnitude of the 24 hour temperature wave that causes it. The demonstration of the existence of the small lunar 12.4 hour and of the much smaller 24.8 hour wave is a recent success, Airy having failed to find even the 12.4 hour wave from an analysis of no fewer than 160,000 hourly observations at Greenwich. These lunar waves are simple gravitational waves owing little to resonance.

An interesting point is that the favourable resonance properties of the atmosphere for the 12 hour and 8 hour waves is apparently fortuitous. If the earth were to lose about thirty per cent of its atmosphere, none of the world-wide oseillations of pressure would be observed.

$$
\text { No. } 3295 \text {, VoL. } 130]
$$

\section{University and Educational Intelligence}

Brrmingham.-At a degree congregation held on December 16, the degree of D.Sc. was conferred on William Leach for numerous published papers on plant ecology and on plant physiology, especially on respiration.

Fourteen candidates also received the degree of Ph.D., namely : two each in physics, civil engineering, mining, metallurgy, and zoology, and one each in botany, chemistry, electrical engineering, and mechanical engineering.

Cambridge.-Dr. T. C. Phemister, of St. John's College, has been appointed University demonstrator in mineralogy and petrology in succession to Dr. A. G. Hutchinson, who has resigned.

Mr. C. F. A. Pantin, of Trinity College, has been nominated to use the University's table at the Zoological Station at Naples.

Dr. R. McG. Carslaw, of St. John's College, has been appointed advisory economist and head of the Farm Eiconomics Branch.

It has been decided that in the regulations for the John Humphrey Plummer professor of inorganic chemistry, the word 'inorganic' should be replaced by 'theoretical'.

EdINBURGH.-The University Court has received with great regret intimation from Sir Edward Sharpey Schafer of his intention to retire from the chair of physiology at the end of the current academical year. He was appointed to the chair in 1899 .

On the recommendation of the Senatus, Dr. J. B. Todd, lecturer in engineering, has been appointed a reader.

London.-Major-General Sir Frederick Maurice, professor of military studies and member of the senate of the University of London, has been appointed principal of East London College as from the commencement of next session in succession to Mr. J. L. S. Hatton.

Prof. H. B. Fantham, professor of zoology in the University of the Witwatersrand, has been appointed Strathcona professor of zoology in McGill University, Montreal, in succession to Prof. A. Willey, and is taking up his new appointment immediately.

THE Cecil Peace Prize for 1932 has been awarded to Mr. A. J. Mackenzie, of the University of Edinburgh, for an essay on "The Danger from the Air. Discuss Possible Methods, by International Convention or otherwise, of dealing with it". This prize of $£ 100$ is offered yearly for an essay on a subject bearing on the principles or work of the League of Nations and is open to students less than twenty-five years of age of any university or university college in Great Britain or Northern Ireland.

THE annual meeting of the Mathematical Association will be held at the Institute of Education, Southampton Row, London, W.C.1, on January 5-6, under the presidency of Prof. G. N. Watson. Several papers will be read and a discussion on "The Study of Statistics in a School Course" will be opened by Mr. F. Sandon. The presidential address, to be delivered on January 5 at 3.45 , will be entitled "The Marquis and the Land Agent: a Tale of the Eighteenth Century". Further particulars can be obtained from the Hon. Secretary, Mr. C. Pendlebury, 39 Burlington Road, Chiswick, W.4. 